\title{
Single-alternation patterning in sated, sucrose-rewarded rats
}

\author{
RICHARD A. BURNS \\ Southeast Missouri State University, Cape Girardeau, Missouri \\ and \\ SUSAN E. GRINER \\ Georgia Southwestern College, Americus, Georgia
}

\begin{abstract}
Rats were runway trained six trials per day for 32 days with alternating values of sucrose rewards (32\% and 4\%), and an interval between trials of about 20 sec. The animals were trained without the motivation of hunger: they were allowed free access to food for $1.5 \mathrm{~h}$ prior to each training session. Patterning developed. Running times were faster, in the later stages of training, for $32 \%$ rewards than for $4 \%$ rewards. Patterning had not been observed in similar experiments with sucrose (Burns, 1976) and hunger-motivated rats.
\end{abstract}

An enduring problem in animal learning concerns the nature of the successive negative contrast effect, a precipitous disruption in the instrumental performance of animals undergoing a reduction in reward value (Flaherty, 1982). There is as yet no clear understanding of the processes that mediate the effect when it occurs, nor is there an account for the numerous situations in which the effect reliably fails to occur. When rats undergo a reduction in the concentration of a sucrose solution used as a reward, their instrumental performance is not disrupted as it usually is when the reward is ordinary food such as Noyes pellets (Flaherty, 1982).

In an early experiment during which rats were given regularly alternating $20 \%$ and $3 \%$ sucrose concentrations as rewards (Burns, 1976), the animals failed to develop patterning, running slower to $3 \%$ than to $20 \%$. Patterning did occur, however, in rats trained with alternating 10 and 1 Noyes-pellet rewards.

In the experiment to be reported here, food deprivation was investigated as a possibly important factor in the failure to find single-alternation patterning with differing concentrations of sucrose. The suggestion that motivational conditions would be worth studying in alternation experiments came from a study in which a reduced sucrose reward disrupted the performance of sated animals (Burns, Ziropadja, \& Djuric, 1984). The many failures to obtain contrast effects with sucrose were conducted with hungry rats.

This work was supported in part by a grant from the Charles L. Mix Foundation to R.A.B. Correspondence should be addressed to R. A. Burns, Department of Psychology, Southeast Missouri State University, One University Plaza, Cape Girardeau, MO 63701 (bitnet: c934huy@semovm).

\section{METHOD}

\section{Subjects}

The subjects were 6 naive, 70-day-old male albino rats obtained from the Holtzman Company, Madison, WI.

\section{Apparatus}

The apparatus was a wooden L-shaped runway $(233.7 \mathrm{~cm}$ long) painted black and covered with hinged, ventilated clear plastic. Manually operated start and retrace doors were positioned 20.3 and $172.7 \mathrm{~cm}$, respectively, from the beginning of the runway. The right turn was $182.9 \mathrm{~cm}$ beyond the start door. Time to travel the first $195.6 \mathrm{~cm}$ of the runway after the opening of the start door was silently recorded when a photobeam positioned at that point was broken by the rat's passage.

\section{Procedure}

The animals were housed in a naturally lighted, windowed colony room in individual living cages with continuous access to water except during 1-h periods following training when the water bottle was replaced by a bottle containing $40 \mathrm{ml}$ of either $32 \%$ sucrose solution (on odd days) or $4 \%$ sucrose solution (on even days). For 2 days after their arrival, the rats were allowed continuous access to food, Purina Rodent Chow, but during the remainder of the experiment, they were allowed food only during a $1.5-\mathrm{h}$ period immediately preceding daily training. On days in which training did not occur, they were given $25 \mathrm{~g}$ of chow.

All animals were allowed to explore the runway with start and retrace doors opened for $5 \mathrm{~min}$ on each of 3 days before 5 days of goalbox placements began. The 1st day of goalbox placements entailed placing each rat in the goalbox with the retrace door closed and the goalcup, a teaspoon mounted on a wooden block, baited with $1 \mathrm{ml}$ of $32 \%$ sucrose. On the 2 nd day, the goalcup was baited with $1 \mathrm{ml}$ of $4 \%$ sucrose. There followed 3 days of placements that involved two placements each day, one with $32 \%$ and the other with $4 \%$ (the two values alternated in coming first).

Runway training then began. For the first 3 days (one "experimental day"), each rat was run in two trials, one with a $32 \%$ reward and one with a $4 \%$ reward. From Experimental Day 2 through the remainder of the experiment (through Day 32), there were six training trials on each day, with the reward values alternating. Whether the first trial of the day ended with $32 \%$ or $4 \%$ alternated from day to day.

The order of running of the animals was determined randomly each day, and each animal was given all six of his daily trials before another animal was run. That procedure makes for an interval between trials of about $20 \mathrm{sec}$. A trial began with the opening of the start door and 


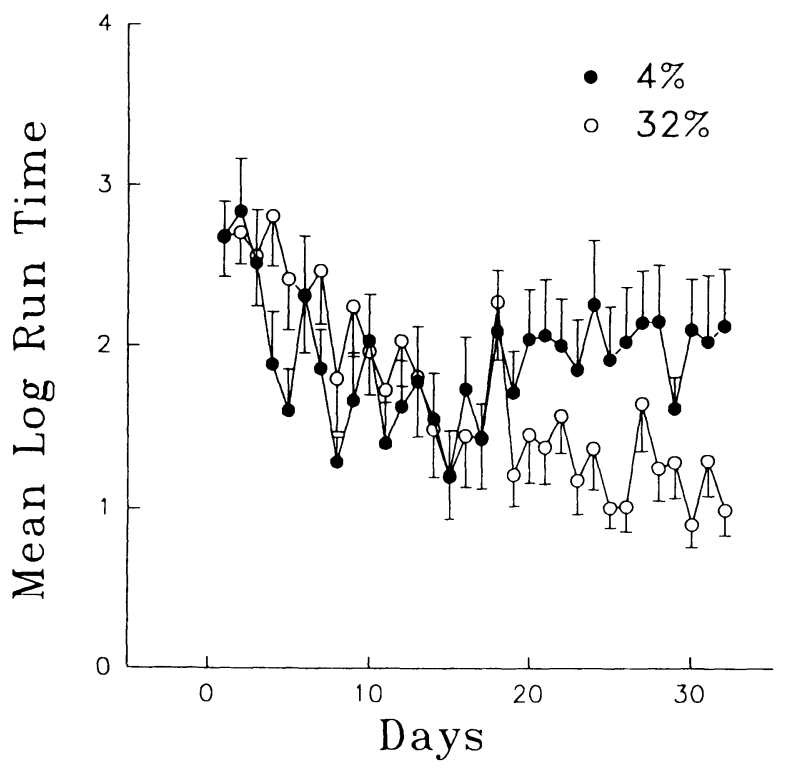

Figure 1. Average transformed running times for each of the alternating reward values, $32 \%$ sucrose and $4 \%$ sucrose, over the 32 days of experimental training.

ended when the animal had consumed the sucrose (or after $2 \mathrm{~min}$, whichever came first). All the animals spent about 15 min together each day following training on a walled exercise table before being returned to their home cages.

\section{RESULTS AND DISCUSSION}

All running time scores were transformed $[x=\log (x)]$ for data analysis. Figure 1 is a plot of the average transformed running times to each of the two reward values over the 32 days of training.

Evident in Figure 1 is the developing tendency for the rats to approach the $32 \%$ sucrose solution more rapidly than the $4 \%$ solution. Analysis of variance over Days 17-32 showed a significant main effect of reward value $[F(1,5)=9.75, p<.05]$. During Days $1-16$, there was a reliable tendency to run more slowly on trials following $4 \%$ rewards than on trials following $32 \%$ rewards $[F(1,5)=7.56, p<.05]$.
Patterning seems best understood as a consequence of carryover or memory of cues arising from the immediately preceding reward value (see, e.g., E. J. Capaldi \& Molina, 1979). Past rewards seem to provide cues for upcoming rewards. In the case in which rewards alternate, as they did in this experiment, the cues arising from $32 \%$ sucrose rewards signal upcoming $4 \%$ rewards and vice versa. From this point of view, a failure to obtain patterning (Burns, 1976) would result from impoverished reward-generated cues, a situation that may also prevent successive contrast (see, e.g., E. J. Capaldi, 1967).

With sucrose rewards, satiation has been shown to amplify the rat's reaction to reward reductions (Burns et al., 1984), and the present experiment suggests that satiation may also be important in the appearance of patterning with sucrose. One possibility is that the effectiveness of sweetness as a source of cues is inversely related to hunger motivation. This conclusion, reached on the basis of patterning and contrast experiments, corresponds to a similar conclusion reached on the basis of work with conditioned food preferences (E. D. Capaldi, Sheffer, \& Owens, 1991).

\section{REFERENCES}

BURNS, R. A. (1976). Effects of sequences of sucrose reward magnitudes with short ITIs in rats. Animal Learning \& Behavior, 4, 473-479.

Burns, R. A., Ziropadja, L., \& DuUric, V. (1984). Effects of liquid sucrose reward reduction on the performance of deprived and nondeprived rats. Journal of General Psychology, 110, 223-228.

Capaldi, E. D., Sheffer, J., \& OWens, J. (1991). Food deprivation and conditioned flavor preferences based on sweetened and unsweetened foods. Animal Learning \& Behavior, 19, 361-368.

CAPALDI, E. J. (1967). A sequential hypothesis of instrumental learning. In $\mathrm{K}$. W. Spence \& J. T. Spence (Eds.), The psychology of learning and motivation (Vol. 1, 67-156). New York: Academic Press.

Capaldi, E. J., \& Molina, P. (1979). Element discriminability as a determinant of serial-pattern learning. Animal Learning \& Behavior, 7, 318-322.

FlaherTy, C. F. (1982). Incentive contrast: A review of behavioral changes following shifts in reward. Animal Learning \& Behavior, 10, 409-440. 